\title{
Correcciones: práctica artística como investigación como quien no quiere la cosa*
}

\author{
Felipe Cussen \\ U. de Santiago de Chile \\ felipecussen@gmail.com
}

\begin{abstract}
Resumen
Este ensayo forma parte del proyecto Fondecyt Regular 1161021 "Poéticas negativas" y está igualmente basado en mi proyecto de creación artística Correcciones. Luego de presentar algunas discusiones actuales en torno a la práctica artística en el espacio académico y narrar las etapas de desarrollo del proyecto de investigación y el proyecto de creación, pretendo demostrar que resulta muy provechoso unir, y no separar artificialmente, ambas dimensiones.
\end{abstract}

Palabras clave

Práctica artística como investigación, Fondecyt, poesía contemporánea, conceptualismo, nada.

\section{Corrections: Artistic Practice as Research and There You Have It}

\begin{abstract}
This essay is part of the Fondecyt Project 1161021, "Poéticas negativas", and is also based on my creative project Corrections. After presenting some current discussions about artistic practice in academic settings and recounting the stages of development of both the research project and the creative project, I aim to demonstrate that it is more productive to unite than to artificially separate both dimensions.
\end{abstract}

Keywords

Artistic Practice as Research, Fondecyt, Contemporary Poetry, Conceptualism, Nothingness.

\section{Correcciones: prática artística como pesquisa como que casualmente}

Resumo

Este ensaio é parte do projeto Fondecyt 1161021 e também é baseado em meu projeto de criação artística Correcciones. Depois de apresentar algumas discussões atuais sobre a prática artística no espaço acadêmico, e narrar as etapas do desenvolvimento

* Recibido: 30 de agosto de 2016 / Aceptado: 14 de octubre de 2016. 
Felipe Cussen. Correcciones: práctica artística como investigación como quien no quiere la cosa.

do projeto de pesquisa e do projeto da criação artística, pretendo demonstrar que é muito útil para unir, e não artificialmente separado, ambas as dimensões.

Palavras-chave

Prática artística como pesquisa, Fondecyt, poesia contemporânea, Concetualismo, Nada. 
Este ensayo forma parte del proyecto Fondecyt Regular 1161021 "Poéticas negativas" ${ }^{1}$, del cual soy investigador responsable, junto a Marcela Labraña y Megumi Andrade como co-investigadoras, y está igualmente basado en mi proyecto de creación artística Correcciones. Esto contraviene de manera expresa las Bases Concurso Nacional de Proyectos Fondecyt Regular 2016, que financia exclusivamente "proyectos de investigación científica y tecnológica" y no financia, en cambio, "proyectos de creación artística, recopilaciones, confección de catálogos o inventarios, impresión de libros, ensayos, traducciones, audiovisuales, textos de enseñanza u otras actividades análogas" (2015: 1; el subrayado es mío) ${ }^{2}$. A pesar de esta distinción tan clara entre la investigación académica y la creación artística junto a otros formatos de escritura, al menos en mi propio caso hubiera sido muy difícil que Correcciones surgiera sin la formulación teórica del proyecto "Poéticas negativas", y, al mismo tiempo, Correcciones resultó ser, en la práctica, una aplicación directa de varios de los presupuestos de "Poéticas negativas", incluso antes de que fuera aprobado e iniciáramos formalmente el proyecto. ¿Cómo ocurre esto?

La actriz, performer y doctora en semiótica María José Contreras ya ha llamado la atención sobre la necesidad de incorporar la conjunción de investigación y práctica artística en el marco de la academia chilena. Se refiere en particular a lo que suele denominarse "arts based research" o "practice-based research"; que ella propone llamar, en el contexto latinoamericano, "práctica como investigación" 3 . Lo que define esta perspectiva es "que las preguntas o motivaciones iniciales solo puedan ser contestadas mediante la práctica. Esto implica que si bien los aspectos conceptuales y la reflexión crítica están presentes, lo crucial sigue siendo la práctica" (2013: 76). De allí que las preguntas de investigación o la hipótesis inicial puedan surgir a posteriori y que la metodología sea necesariamente emergente, lo que conlleva lidiar con una alta dosis de incertidumbre (2013: 77).

\footnotetext{
${ }^{1}$ La mención a Fondecyt es un requisito esencial para que una publicación sea validada como producto del proyecto de investigación.

${ }^{2}$ Esta advertencia se ha mantenido idéntica al menos desde el concurso para el año 2003 (las primeras bases que están disponibles en la página web de Fondecyt) hasta la reciente convocatoria para el año 2017.

3 Tal como explica María José Contreras, la "arts-based research" se "asocia en general al ámbito de la educación y pretende revelar la importancia de las artes en los procesos de aprendizaje y enseñanza" (2013: 74), pero en este texto ella se enfoca "en otro ámbito definido ampliamente como investigación basada en la práctica o investigación conducida por la práctica que define un tipo de investigación realizada en programas de postgrado que consideran el trabajo de taller como crucial en el desarrollo investigativo", y que corresponde también a mi interés en este ensayo.
} 
En el marco de nuestro proyecto, hemos realizado regularmente algunas sesiones de trabajo con otros investigadores y artistas. En una de ellas, tuvimos la oportunidad de que María José nos presentara el proyecto "Valor!", que realizó con los arquitectos Carolina Ihle y Fernando Portal mediante una serie de ocho sitespecific performances en Mil M2 ${ }^{4}$. Tal como ella señaló, los presupuestos planteados en el diseño original, que había obtenido un fondo en el Concurso de Creación y Cultura Artística 2014 de la Pontificia Universidad Católica de Chile, cambiaron mucho durante su desarrollo y obligaron a plantearse nuevas preguntas. No se trata, entonces, de programar una secuencia de etapas inamovibles, sino que, como señalan María Inés Silva y Alejandro Vera, en estos casos se origina un "proceso investigativo cíclico que [Brad] Haseman ha descrito de la forma siguiente: 1) el artista-investigador planea un cambio en relación con los materiales disponibles; 2) efectúa y observa el proceso; 3) reflexiona sobre el mismo y sus consecuencias; y 4) esto lo lleva a replantear el plan original y plantear nuevos cambios, etc." (2010: 30) $)^{5}$. Hay que enfatizar, entonces, que la práctica artística no se limita a ser el objeto de estudio ni tampoco una mera ilustración de sus resultados, sino que constituye el medio a través del cual se investiga.

María José Contreras insiste, asimismo, en que este cambio de paradigma implica, en definitiva, un proyecto político, pues se propone modificar una tradición epistemológica muy fuerte, propia de las ciencias, que se ha transplantado sin mayor crítica a las artes y humanidades. La práctica como investigación "es también un efectivo antídoto a lo que Michel Foucault llamó el disciplinamiento de los saberes que implica la normalización, distribución y jerarquización del conocimiento" (2013: 81), pues impugna la hegemonía del texto escrito como único vehículo de conocimiento, borra la frontera entre saber teórico y práctico y hace necesario que "las disciplinas colaboren en una configuración posdisciplinar" (2013: 82).

Hoy en día existen numerosos programas de postgrado que admiten con diversas variantes la integración entre reflexión y creación, particularmente en países anglosajones, pero también en Brasil y, tímidamente, en Chile. El Doctorado en Artes de la Universidad Católica (en cuyo diseño participaron, entre otros, María José Contreras y Alejandro Vera) lo propone de manera explícita, al igual que el reciente Magíster en Investigación y Creación Artística de la Universidad Mayor, y también en el Magíster en Arte, Pensamiento y Cultura Latinoamericanos del

\footnotetext{
${ }^{4}$ Para más información sobre éste y otros proyectos de María José Contreras, ver su página web: http://www.mariajosecontreras.com.

${ }^{5}$ Para una información más amplia sobre las principales discusiones en este ámbito, ver Sullivan (2005) y los libros colectivos editados por Barrett y Bolt (2007) y Knowles y Cole (2007).
} 
Instituto de Estudios Avanzados de la Universidad de Santiago de Chile, donde admitimos la posibilidad de una tesis "mixta". Incluso en un programa más "tradicional", como el Doctorado en Filosofía con mención en estética por la Universidad de Chile, Demian Schopf (2015) presentó una interesante tesis en la que analizaba una obra de arte digital del alemán David Link y otra de su propia creación ${ }^{6}$. Asimismo, a nivel de publicaciones, es interesante la aparición de esta misma revista, Panambí, nacida al interior del Doctorado en Estudios Interdisciplinarios de la Universidad de Valparaíso, y que privilegia la investigación que surge desde la creación artística. Por otra parte, en las discusiones del Grupo de Investigadores en Artes y Humanidades (que surgió a partir de la inminente creación de un Ministerio de Ciencia y Tecnología), el equipo encargado de estudiar específicamente la situación de las artes en la investigación académica ha planteado la necesidad de incorporar la práctica como investigación dentro del formato de proyectos Fondecyt. Es preciso señalar, sin embargo, que algunos miembros de dicho equipo no compartían esta intención, pues les preocupaba que se provocara una confusión con la práctica artística a secas y que fuéramos relegados al futuro Ministerio de las Culturas y sus fondos artísticos. Cuando se conversó en una reunión ampliada, fue notorio que gran parte de los investigadores, especialmente de disciplinas como literatura, lingüística, filosofía o historia, ni siquiera sabían de la existencia y la validez de la práctica como investigación.

En mi caso, de hecho, aunque tenía algunas vagas nociones, sólo el año 2015 pude conocer mejor los detalles y alcances de esta forma de trabajo. Inmediatamente me llamó la atención y me pareció un acercamiento bastante natural, dado que, en el campo de la literatura, en el que suelo moverme, siempre me han atraído las reflexiones de los escritores sobre sus prácticas o las de otros y yo mismo he escrito varios ensayos que pueden englobarse en el género de "poéticas", entendidas como una reflexión a partir de las estrategias y procedimientos desarrollados desde la creación propia. Algunos de ellos, como "La voz del poeta" y "Quise grabar un disco de poesía sonora, pero me salió música electrónica", fueron escritos en el marco de un proyecto Fondecyt anterior, "Samples y loops en la poesía contemporánea", en el que trabajé junto al músico electrónico Ricardo Luna, quien, además, me enseñó algunos rudimentos de la programación en el software Ableton Live ${ }^{7}$. Esa confluencia de intereses, sin embargo, no nos permite hablar, en estricto rigor, de una práctica artística como investigación, pues aquellos textos son más bien una reflexión a posteriori de determinados procesos creativos, antes que el producto de una interrelación más estrecha. Algo similar ha ocurrido en la relación entre "Poéticas negativas" y Correcciones, pues

\footnotetext{
${ }^{6}$ El título de la tesis fue Máquina de coser. Máquinas lógicas, autómatas poéticos y lenguaje natural en las artes mediales contemporáneas.
}

${ }^{7}$ Respecto a este proceso, ver Cussen, 2015a. 
se trata de proyectos planificados de manera separada, con sus propias metodologías y etapas. No imaginaba que se podría producir esta contaminación entre ambos, pero deseo relatar este proceso como un recuento de lo que sólo me atrevería a llamar, antes de que los expertos frunzan el ceño, "práctica artística como investigación como quien no quiere la cosa".

\section{2.}

El proyecto "Poéticas negativas" nació de búsquedas anteriores de sus tres investigadores, en particular la relación entre la poesía y la mística, las representaciones del silencio en la literatura y las artes visuales, y diversas formas de escritura caligráfica que resultan ilegibles. Ahora queríamos profundizar en la posibilidad o imposibilidad del lenguaje para referir algo que está ausente, oculto o que pareciera ser inaprensible mediante las palabras; una tensión cuyos orígenes situábamos en la tradición de la teología negativa o apofática (que, tal como se conoce desde Dionisio Areopagita en el siglo V, se fundamenta en la incapacidad para definir a dios) y que podía vislumbrarse en numerosos escritores y artistas contemporáneos. La formulación de nuestra investigación fue muy convencional: incluimos las definiciones operativas con que trabajaríamos ("nada", "discurso apofático", "negatividad", etc.), una revisión histórica de estas perspectivas y una descripción detallada de nuestro corpus de estudio, que abarca desde novelas en las que no ocurre nada hasta libros con todas sus páginas en blanco e, incluso, obras inexistentes. Dedicamos una sección especial para distinguir algunas dimensiones de análisis fundamentales, con el fin de trabajar a partir de la ausencia de una trama o un mensaje explícitos. Proponíamos que resultaba urgente considerar la dimensión paratextual de estas obras (nombre del autor, título, índice, colofón, etc.) para poder enmarcar y ayudar a determinar el sentido que se escapa y, al mismo tiempo, su materialidad (ya sea la tipografía, la diagramación, los tipos de hoja, etc.) que, en estos casos, deja de ser un aspecto secundario y pasa a primer plano. Dentro de los objetivos del proyecto no incluimos nada que tuviera que ver directamente con la práctica artística, aunque, al menos, quisimos dejar establecido que deseábamos vincular los avances de esta investigación con la creación y la reflexión de escritores y artistas contemporáneos, mediante diálogos, talleres y otras actividades de difusión.

Mi propio interés por la nada y las diversas formas de negatividad no sólo provenía de mis estudios en esta área, sino también algunos intentos en la escritura. Uno de ellos fue el poema visual "Este poema jamás desaparecerá": 


\section{ES TE POEMA JAMAS DESAPAREQERA. ESTE P OEMA JAMAS DESAPAREQERA. ESTE POEMA JAMAS DESAPAREQERA. ESTE POEMA JAMAS DESAPAREQERA. ESTE POE WA JAMAS DESAPAREGERA. ESTE POEMA JAMAS DESAPARERERA.}

Figura 1. Felipe Cussen, "Este poema jamás desaparecerá", poema visual exhibido el año 2008 en una instalación en el Consejo Nacional de la Cultura y las Artes, Valparaíso.

Dentro de los poemas que aparecieron publicados en la antología Diecinueve, editada por Francisca Lange, también incluí un poema ausente aludido sólo mediante notas al pie -“Ya no sé cómo decir 'Te quiero'..." (en Lange, 2006: 86-88)y otro poema oculto:

Dentro de este sobre tengo guardado un poema muy bueno, demasiado bueno, pero no pienso mostrárselos, porque si no, tremenda gracia.

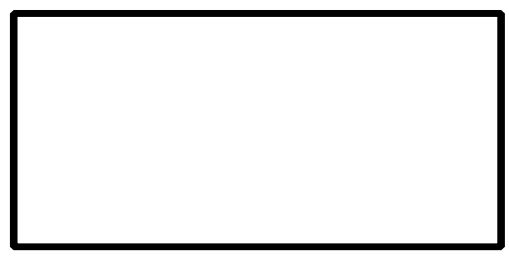

Figura 2. Felipe Cussen, "Poema" (en: Lange, 2006: 85).

También realicé, el año 2002, un ejercicio titulado El secreto de la poesía, que consistía en un correo spam enviado a algunos amigos y páginas web:

¿Cuántas veces has querido conocer cuál es el secreto que se oculta detrás de todo gran poema, aquello que parece no poder explicarse con palabras?

Ahora tienes, por fin, la oportunidad de conocerlo. Para recibir la información que ofrecemos de forma gratuita sólo tienes que responder este mail, escribiendo "SÍ, QUIERO".

¡Te esperamos! 
Tus amigos de EL SECRETO DE LA POESÍA, S.A.

P.D.: Envía este mail a tus personas queridas para que ellos también puedan conocer el secreto de la poesía

(Cussen, 2002).

Si es que alguien contestaba, simplemente le respondía de vuelta un mensaje sin asunto ni nada adentro. Recibí unas cinco o seis respuestas, algunas de un par de amigos que me escribieron contándome de este mail porque pensaban que me interesaría, sin saber que yo lo había enviado.

Correcciones tuvo como punto de partida una práctica común entre los poetas: pedirle a un amigo que revise un poema. En este caso, consistía en tomar un poema escrito previamente por mí, y pedirle a distintos poetas, ojalá algunos cuyas estéticas fueran muy distintas a la mía o que derechamente me cayeran mal, que lo corrigieran sucesivamente. Mi deseo era que funcionara como el juego del teléfono y que se fueran mostrando las distintas mutaciones que lo alejaban del poema original. También se me ocurrió, paralelamente, que podría enviarlo a esos talleres en línea donde realizan comentarios. Después pensé que sería mejor aún si es que el poema original sobre el que se harían las variaciones sucesivas era un poema ajeno, para que así no hubiera nada mío aparte de los procedimientos. De todos modos, como este proyecto estaba concebido como una cadena, sería bastante lento de realizar, pues dependería de la velocidad de respuesta de cada uno de los invitados.

El año pasado, más precisamente el 5 de agosto de 2015 (precisamente cuando nos encontrábamos en medio de la postulación del proyecto de investigación) anoté otra idea que funcionaba de manera más sencilla: "pedirle a muchos poetas (de distintos países, en distintos idiomas) que me aconsejen cómo mejorar un poema (correcciones, adiciones, supresiones, etc.), pero ese poema no existe, y publicar sólo esos comentarios y sugerencias" (Cussen 2015b). Ahí pensé que este proyecto se podría desarrollar en un tiempo más acotado, pues establecería un plazo preciso para recibir las respuestas y también podría incluir a otros amigos y conocidos que no fueran poetas. Se llamaría Correcciones.

Cuando la anoté, tenía en mente un libro muy interesante que había recibido hace poco, On the Subcontract, de Nick Thurston. Este libro fue escrito gracias a la utilización de Amazon Mechanical Turk, una plataforma en la que se puede pagar por distintos tipos de servicios. Mediante ella, el autor subcontrató a trabajadores anónimos para que produjeran los cien poemas que conforman su libro. Antes, Vladimir Zykov había desarrollado I Was Told to Write Fifty Words gracias a la misma plataforma y pagó a sus precarizados empleados un centavo de dólar por cada palabra (Dworkin \& Goldsmith, 2011: 581-586). Mi proyecto, en cambio, no contemplaba ningún pago, sino la buena voluntad de sus participantes; se acercaba un poco más a la larga tradición de obras colaborativas dentro del arte postal y el net-art, en la 
que suelen realizarse convocatorias en torno a algún tema específico para luego recolectarlas y disponerlas de manera conjunta.

Dejé reposar la idea algunas semanas, pero un domingo en la mañana, el 27 de septiembre, decidí impulsivamente echar a andar el proyecto. Escribí el siguiente correo en español (y también en inglés) para distintos amigos y conocidos:

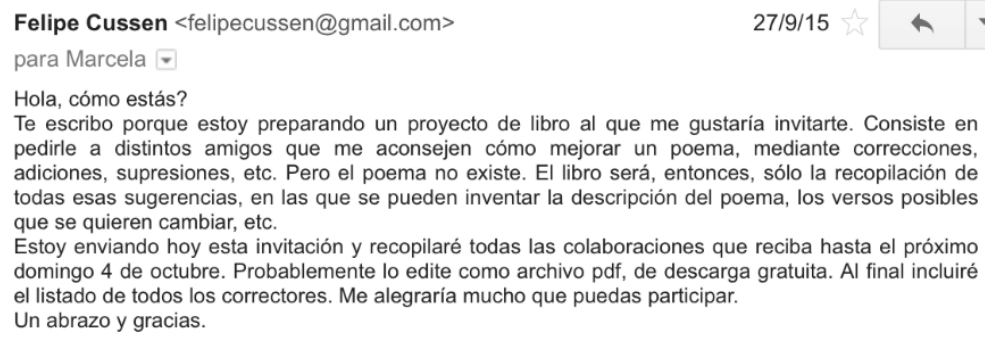

Figura 3. Felipe Cussen, mensaje de correo.e del 27 de septiembre de 2015.

Además, quise convocar a otros posibles interesados en Facebook, y escribí durante esos mismos días un mensaje algo enigmático: "Necesito ayuda para corregir un poema. Quienes puedan ayudarme, por favor enviar MP. Gracias", y a quienes respondieran les enviaba las instrucciones. Mi intención era agrupar todo lo que recibiera en dos volúmenes distintos, de acuerdo a los idiomas (Correcciones y Corrections). Recibí muchísimas respuestas por ambas vías, obviamente una mayor parte de ellas en español, que cumplían precisamente con el objetivo de obligar a visualizar las características de aquel poema inexistente y cómo debería ser corregido. Lo pensé como un focus group: pensé que esto sería un modo de hacer un "retrato hablado" de cómo distintas personas supondrían que sería un poema mío, pero creo que algunos de ellos imaginaron más bien sus propios poemas potenciales. Antes de ordenarlas, edité o acorté algunas de estas correcciones, para darles una mayor homogeneidad. En ese sentido, mi práctica se alejaba de la no intervención característica del arte postal y, de algún modo, me convertía en el corrector de mis propios correctores. Éstas son algunas: "He leído y releído el poema que me enviaste. Me parece muy valiente cómo abres tu corazón y cómo toda palabra que tocas se inunda con tus sentimientos. Versos como 'los ojos de mi alma' o 'la llave de mi corazón' son muy potentes y hablan de tu atormentada y sensible mirada de poeta" (Gregorio Fontaine); "Lenguaje demasiado hermético. Falta luz y aire. Mejora a partir de la segunda parte" (Camilo Brodsky); "Si quieres hacer poemas de amor homosexual con un tono barroco, me parece 
muy bien, es un ejercicio divertido, hilarante, aunque en extremo maraco" (Corrales!); "While your beginning is strong, I lose focus when you split syntax between the ' $l$ ' and the sudden inclusion of the lower case ' $i$ './ Try inverting the last line of the first stanza by placing yourself at the middle and then remove that mention of 'other' by regurgitating the promise you started with" (Edwin Torres); "Change the title./ Change the ending" (Steve Dalachinsky).

Lo que he descrito hasta aquí corresponde de manera bastante exacta a lo que había pensado inicialmente: reunir descripciones textuales en torno a nada, miradas concéntricas dirigidas hacia un centro ausente. Pero desde que lancé la convocatoria, recibí una gran cantidad de respuestas que no estaban planificadas y que podríamos calificar de excéntricas, pues dirigían la atención hacia otras dimensiones. Se fue conformando así este grupo, que decidí separar del proyecto anterior y concebir como una antología más abierta, que pensé titular Etc., en la que también incluí respuestas sin un énfasis visual, pero muy extensas, $u$ otras donde comentaban el juego del proyecto o argumentaban de manera demasiado explícita respecto a mi invitación y al poema inexistente, por lo que develaban el artilugio antes de tiempo.

La primera de estas respuestas provino precisamente de Nick Thurston, quien me envío una versión corregida no de mi poema inexistente, sino de las imprecisiones y errores de mi mail en inglés y, a continuación, sólo las marcas de sus tachaduras:

Felipe Cussen
To: Nick Thurston, Gordon Faylor, Josef Kaplan, Stephen MoCaffery, Julien Blaine, Julio Terra, 27 September $201515: 98$
Kenneth Goldsmith / UbuWeb, Kim Rosenfield, kmm52@buffalo.edu, kristen gallagher, Lanny Jordan Jackson,
Lawrence Gilfin, Lawrence Upton, Michael Basinski, Vanessa Place, Annette Gilbert, Tyler Cobum, Angela Genusa,
Monica de la Torre, Patrick Lovelace, Sam Winston, suzyRB@ils.com.au, yedda morrison, William Andrew Sterling.
John Paetsch, Edward Hopely
Gerreetions Corrected

Dear friends, T'm writing to you because ilm preparing a book project if which l'd like to invite you'? rrs'about asking some friends how should I I improve a poem with corrections, additions, substractions, etc. But the poem doesn' exist. The book will be bonly] the recollection of all these suggestions, Where you can invent a description of the poem, the possible lines that you'd like to change, etc. I'm sending this invitation today and I'lliegleet all contributions received by sunday october 4 th. Ill probably release it as a free PDF

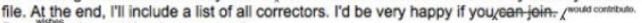

Best regards, and thanks very much.

Felipe

Felipe Cussen

Investigador Instituto de Estudios Avanzados

Universidad de Santiago de Chile

http://usach.academia.edu/FelipeCussen

Figura 4. Corrección de Nick Thurston

También recibí mi propio correo tachado completamente por Serkan Ozkaya, y Paula Dittborn me envió sus correcciones en el formato propio de Word: 
Dear friends, I'm writing to you because i'm preparing a book project in which l'd like to invite you. It's about asking some friends how should I improve a poem with corrections, additions, substractions, etc. But the poem doesn't exist. The book will be only the recollection of all these suggestions, where you can invent a description of the poem, the possible lines that you'd like to change, etc.

I'm sending this invitation today and I'll collect all contributions received by sunday october 4 th. I'll probably release it as a free PDF file. At the end, I'll inelude a list of all correctors. I'd be very happy if you can join.

Best regards, and thanks very much.

Figura 5. Corrección de Serkan Ozkaya

\begin{tabular}{|c|}
\hline Paula Dittborn 9/27/2015 9:55 PM \\
\hline Comentario [1]: \\
\hline Paula Dittborn 9/27/2015 9:55 PM \\
\hline Eliminado: \\
\hline Paula Dittborn 9/27/2015 9:56 PM \\
\hline Con formato: Fuente: Negrita \\
\hline Paula Dittborn 9/27/2015 9:57 PM \\
\hline Comentario [2]: \\
\hline Paula Dittborn 9/27/2015 9:57 PM \\
\hline Eliminado: . \\
\hline Paula Dittborn 9/27/2015 9:57 PM \\
\hline Con formato: Fuente: Negrita \\
\hline Paula Dittborn 9/27/2015 9:57 PM \\
\hline Comentario [3]: \\
\hline Paula Dittborn 9/27/2015 9:57 PM \\
\hline Eliminado: \\
\hline Paula Dittborn 9/27/2015 9:57 PM \\
\hline Con formato: Fuente: Negrita \\
\hline Paula Dittborn 9/27/2015 9:57 PM \\
\hline Comentario [4]: \\
\hline Paula Dittborn 9/27/2015 9:57 PM \\
\hline Eliminado: \\
\hline Paula Dittborn 9/27/2015 9:57 PM \\
\hline Con formato: Fuente: Negrita \\
\hline Paula Dittborn 9/27/2015 9:57 PM \\
\hline Comentario [5]: \\
\hline Paula Dittborn 9/27/2015 9:57 PM \\
\hline Eliminado: \\
\hline Paula Dittborn 9/27/2015 9:57 PM \\
\hline Con formato: Fuente: Negrita \\
\hline Paula Dittborn 9/27/2015 9:58 PM \\
\hline Comentario [6]: \\
\hline Paula Dittborn 9/27/2015 9:58 PM \\
\hline Eliminado: \\
\hline Paula Dittborn 9/27/2015 9:58 PM \\
\hline Con formato: Fuente: Negrita \\
\hline Paula Dittborn 9/27/2015 9:58 PM \\
\hline Comentario [7]: \\
\hline Paula Dittborn 9/27/2015 9:58 PM \\
\hline Eliminado: \\
\hline Paula Dittborn 9/27/2015 9:58 PM \\
\hline Con formato: Fuente: Negrita \\
\hline
\end{tabular}

Figura 6. Corrección de Paula Dittborn

Otros amigos fueron más allá y realizaron trabajos físicos que ponían de relieve este trabajo de corrección, como Carlos Almonte, Natalia Matzner y Tomás Browne: 
Felipe Cussen. Correcciones: práctica artística como investigación como quien no quiere la cosa.

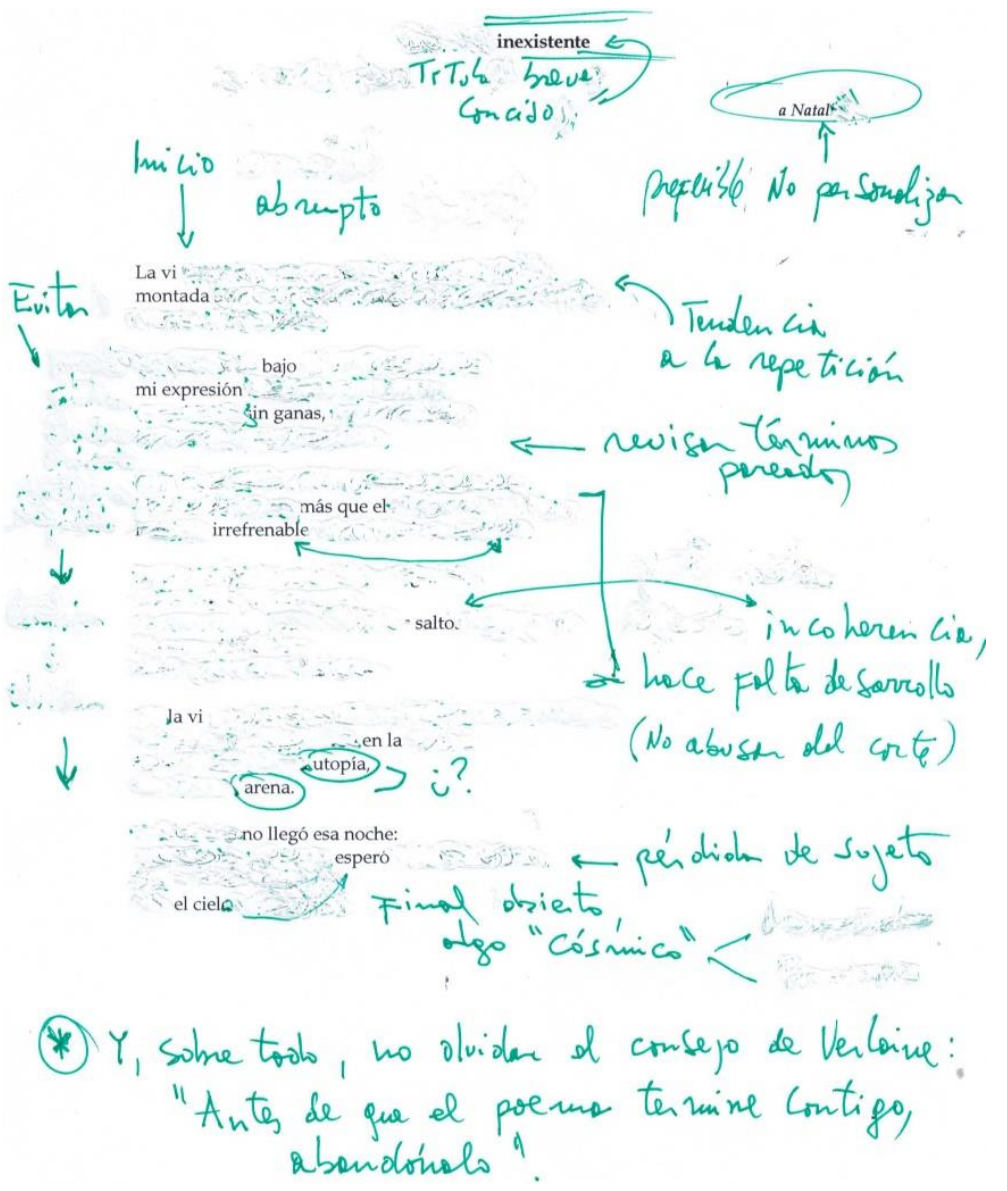

Figura 7. Corrección de Carlos Almonte

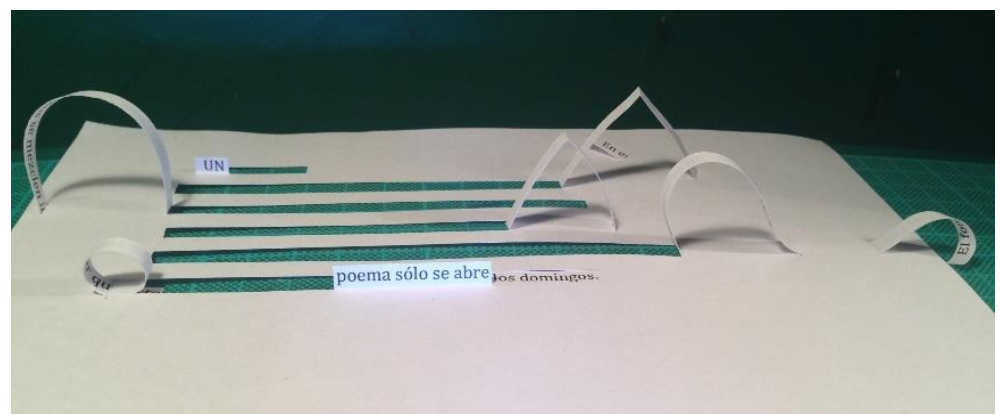

Figura 8. Corrección de Natalia Matzner 


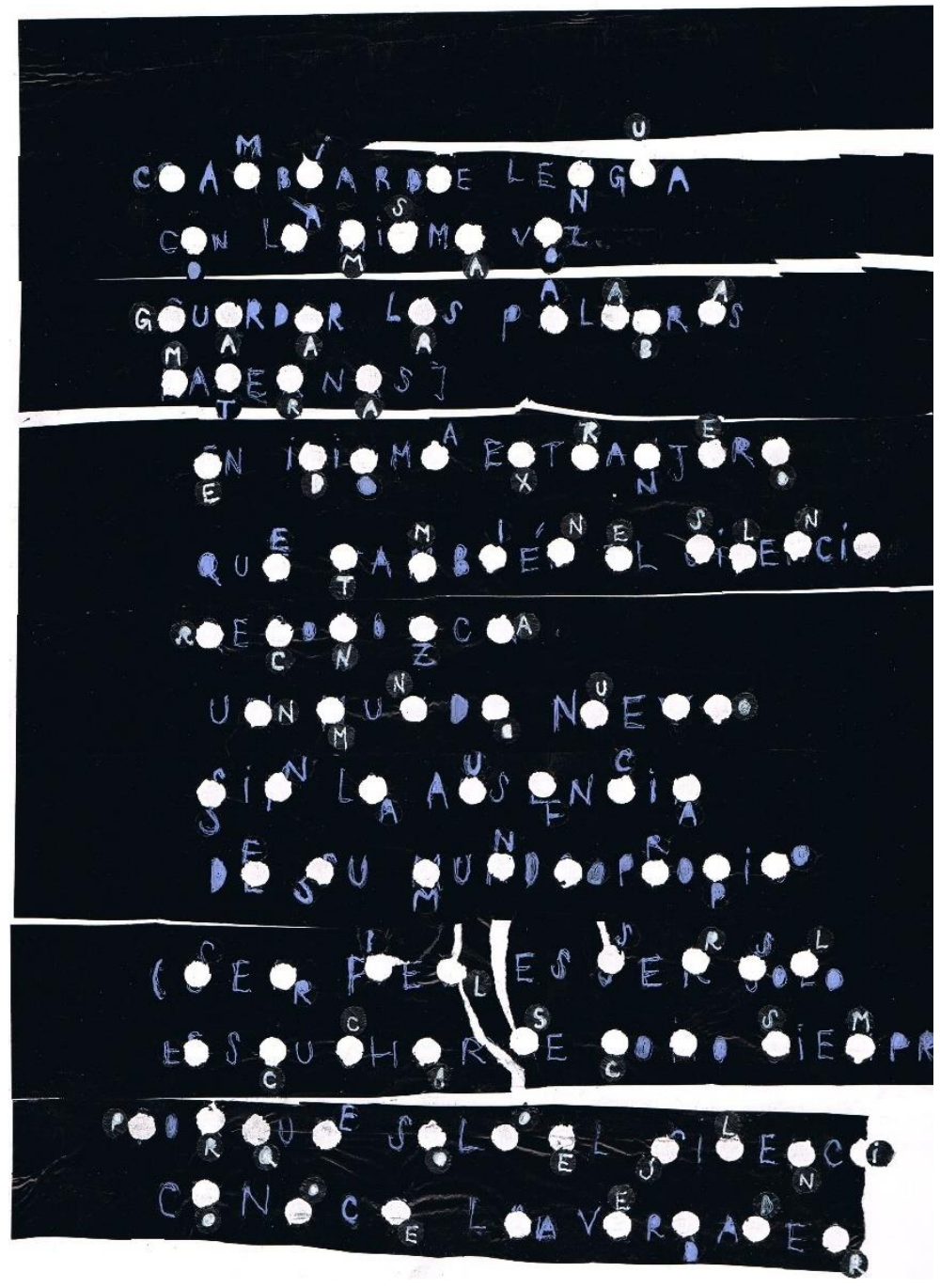

Figura 9. Corrección de Tomás Browne

Jörg Piringer, por su parte, me envió el código de un programa, que evidentemente no he podido ejecutar, y Andrea Wolf aplicó un algoritmo para distorsionar la imagen de mi propio correo: 
Felipe Cussen. Correcciones: práctica artística como investigación como quien no quiere la cosa.

\#! /usr/bin/env lua

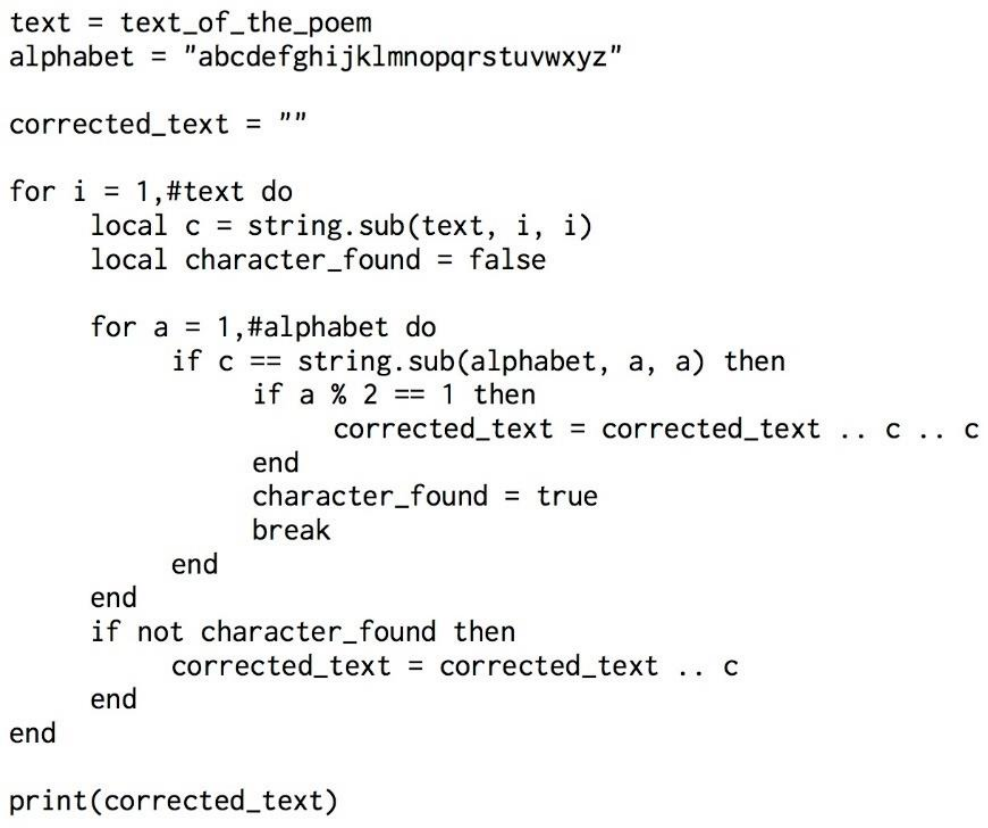

Figura 10. Corrección de Jörg Piringer

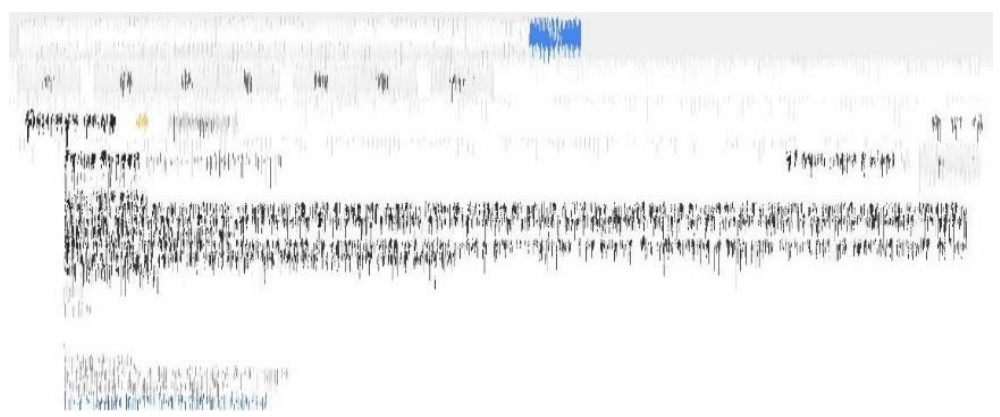

Figura 11. Corrección de Andrea Wolf 
Todos ellos me permitieron darme cuenta de manera muy directa de uno de los aspectos de análisis fundamentales en nuestro proyecto "Poéticas negativas": la materialidad. Aunque había pensado que Correcciones sería una recopilación de obras mentales, estas respuestas obligaban a poner atención no sólo en su tipografía, sino también en los trazos, el relieve, las tachaduras y, además, los pixeles que componen cada letra.

Mientras iba organizando todo este conjunto, pensé que sería interesante proponer este proyecto como publicación digital a un grupo de poetas y editores amigos (Craig Dworkin, Nick Thurston y Simon Morris) que están a cargo de Information as Material, en el que han publicado numerosas obras que pueden considerarse dentro del ámbito del conceptualismo e incluso prepararon una antología titulada NOTHING: A User's Manual. Cuando Craig (quien además es autor de No Medium, un interesantísimo estudio sobre obras vacías, borradas o silenciosas) visitó Chile en noviembre pasado, nos reunimos para trabajar en la edición, pero no discutimos nada del contenido del libro (ni tampoco la tipografía Bodoni, porque le dije que siempre había querido hacer un libro con esa tipografía), sino que más bien sobre cómo trabajaríamos los elementos paratextuales y la distribución -justamente, la otra dimensión relevante para el análisis de este tipo de obras, de acuerdo a nuestra investigación. Craig estuvo de acuerdo con mi opción de colocar los nombres de los correctores en un índice en la última página, al final del cual aparecería mi nombre como "autor" del proyecto, la editorial y el año. Yo, además, había considerado incluir una nota explicativa al final de cada volumen, pero decidimos quitarla, porque estimamos que la inclusión de mi propio e.mail al final del tercer volumen ya era suficiente explicación. Coincidimos en que correspondía subirlo como archivo en pdf para descarga gratuita, pues resultaba acorde a su espíritu colectivo.

Dejé descansar el proyecto unos meses y opté por regularizar los títulos: en vez de que cada volumen se llamara Correcciones, Corrections y Etc., preferí llamarlos genéricamente Correcciones a los tres, para englobarlos bajo un solo proyecto, independientemente de la diversidad de idiomas que incluía. Nos volvimos a contactar con Nick y Craig para ver los detalles de la página web. Los archivos en pdf estarían ubicados en el archivo Eclipse, de University of Utah (especializado en poesía experimental en inglés), y sólo se verían los títulos, nada más. En la página web de Information as Material, desde la que se accedería, sí tuvimos que incluir algunos datos (cantidad de volúmenes y páginas, costo, año, etc.) y me pidieron además una pequeña descripción.

Aquí me vi enfrentado a una disyuntiva interesante: en casi todos mis libros anteriores, nunca puse nada más que mi nombre y traté de evitar cualquier texto de presentación o lo que pudiera funcionar como etiqueta. Sólo en uno de ellos, Deshuesos, de 2007, tuve que incluir una mínima biografía y mencioné lo único 
de lo que me siento orgulloso: que nunca fui boy scout. Como el libro era muy hermético, creo que eso fue lo único que se entendió y las pocas reseñas que aparecieron se fijaron en exceso en mi particular condición. Ahora, en cambio, decidí ocupar todos estos elementos del envoltorio como parte de la obra misma, e incluí ese mismo texto en un correo que envié a los colaboradores y a otros amigos, en el que resumía de manera más dramática mis peripecias y sumaba a uno de los autores invitados que no pudo participar:

Felipe Cussen estaba en problemas. Necesitaba ayuda para corregir un poema. Hizo un desesperado llamado a sus amigos y conocidos. Los tres volúmenes de Correcciones son el resultado: http://www.informationasmaterial.org.

"Querido Felipe: no creo que pueda enviarte nada, porque no tengo ideas acerca de la corrección de un poema. Un abrazo desde París" (Enrique Vila-Matas, autor de Bartleby y compañía).

La elección de Vila-Matas no fue casual; yo acababa de escribir unas líneas de contratapa para la reedición de uno de sus libros en Chile, pero, además, su libro Bartleby y compañía estaban muy cerca de las poéticas negativas:

Me dispongo, pues, a pasear por el laberinto del No, por los senderos de la más perturbadora y atractiva tendencia de las literaturas contemporáneas: una tendencia en la que se encuentra el único camino que queda abierto a la auténtica creación literaria; una tendencia que se pregunta qué es la escritura y dónde está y que merodea alrededor de la imposibilidad de la misma [...].

Sólo de la pulsión negativa, sólo del laberinto del No puede surgir la escritura por venir. [...] Estoy convencido de que sólo del rastreo del laberinto del No pueden surgir los caminos que quedan abiertos para la escritura que viene. A ver si soy capaz de sugerirlos. Escribiré notas a pie de página que comentarán un texto invisible, y no por eso inexistente, ya que muy bien podría ser que ese texto fantasma acabe quedando como en suspensión en la literatura del próximo milenio.

(Vila-Matas, 2000: 12-13)

A pesar de estos cálculos y prevenciones, cuando finalmente lo difundí a mediados de mayo de 2015, hubo muchos, como mi padre, que pensaron que todo esto era un spam. Otros apenas lo hojearon y se fijaron en el índice de colaboradores, como quien revisa la lista de amigos en común de un perfil de Facebook. Los que sí lo leyeron completo lo encontraron entretenido y eso ya me deja muy feliz.

En el intertanto, a fines de enero de 2016, supimos que nuestra postulación a Fondecyt había sido aceptada y comenzamos a trabajar en el proyecto desde abril. De todos modos, tanto yo como Marcela y Megumi (que conocían y habían participado en Correcciones) teníamos la sensación de que ya habíamos avanzado un poco al poder comprobar la relevancia de la dimensión material de la nada, así como del rol crucial de los paratextos en obras de este tipo. Hay otro elemento 
no previsto, pero muy relevante, que emergió con más fuerza gracias a Correcciones: el carácter ambiguo, irónico e incluso chistoso de las disquisiciones sobre nada. Este carácter ya estaba presente en proyectos anteriores, como "El secreto de la poesía", pero su aparición nos ha obligado a tener en cuenta, en nuestra investigación, que las poéticas negativas no siempre son profundas y religiosas, sino que también pueden desplegarse con mayor levedad y potencial crítico.

Es cierto que "Poéticas negativas" no es estrictamente un proyecto de práctica como investigación, pero, a estas alturas, me resulta indudable que, gracias a mis ejercicios creativos previos, se produjeron cruces y contaminaciones beneficiosos, que me han ayudado a pensar y poner en práctica la nada de maneras más diversas y complejas. Por eso, creo que estoy haciendo un poco de justicia al escribir este ensayo porque, aunque sea imposible encontrarlo en algún formulario de postulación, el poema inexistente de Correcciones es también uno de los núcleos que late en nuestras "Poéticas negativas".

\section{Referencias}

Barrett, Estelle; Bolt, Barbara; eds. (2007). Practice as Research: Approaches to Creative Arts Inquiry. New York: St Martin's Press.

Fondecyt (2015). Bases Concurso Nacional de Proyectos Fondecyt Regular 2016". Santiago: Fondecyt. Recuperado el 28 de agosto de 2016 de http://www.conicyt.cl/fondecyt/files/2015/04/BASES-FONDECYT-REGULAR-2016.pdf.

Contreras, María José (2013). “La práctica como investigación: nuevas metodologías para la academia latinoamericana". Poiésis (21-22), jul-dic. 71-86.

(SF). María José Contreras Lorenzini (sitio web). En línea: http://www.mariajosecontreras.com

Cussen, Felipe (2016). Correcciones. York: Information as Material. Recuperado el 26 de agosto de 2016 de http://www.informationasmaterial.org/portfolio/correcciones/.

(2015b). Notas sobre Correcciones. Inédito.

(2015a). "Poeta y académico. Una breve autobiografía crítica". La Calle Passy 061, 13 de octubre. Recuperado el 31 de agosto de 2016 de http://lacallepassy061.blogspot.cl/2015/10/poeta-y-academico-una-breve.html.

(2014b). "Quise grabar un disco de poesía sonora, pero me salió música electrónica". Revista CECLI, 23 de julio. Recuperado el 31 de agosto de 2016 de http://ceclirevista.wordpress.com/2014/07/23/quise-grabar-un-disco-de-poesiasonora-pero-me-salio-musica-electronica/. 
Felipe Cussen. Correcciones: práctica artística como investigación como quien no quiere la cosa.

(2014a). "La voz del poeta". Revista CECLI, 26 de marzo. Recuperado el 31 de agosto de 2016 de http://ceclirevista.wordpress.com/2014/03/26/la-voz-delpoeta-2/.

(2007). Deshuesos. Santiago: Animita Cartonera.

(2002). El secreto de la poesía. Cadena de e-mails.

Dworkin, Craig. No Medium (2013). Cambridge: The MIT Press.

Dworkin, Craig; Kenneth Goldsmith; eds. (2011). Against Expression. An Anthology of Conceptual Writing. Evanston: Northwestern University Press.

Information as Material, ed. (2015). NOTHING: A User's Manual. York: Information as Material. Recuperado el 26 de agosto de 2016 de http://www.informationasmaterial.org/portfolio/nothing-a-users-manual/.

Knowles, Gary; Cole, Ardra; eds. (2007). Handbook of the Arts in Qualitative Research: Perspectives, Methodologies, Examples, and Issues. Los Angeles: Sage.

Lange, Francisca, ed. (2006). Diecinueve (Poetas chilenos de los noventa). Santiago: J. C. Sáez.

Silva, María Inés; Vera, Alejandro (2010). Proyectos en arte y cultura. Criterios y estrategias para su formulación. Santiago: UC.

Sullivan, Graeme (2005). Art practice as Research: inquiry in the visual arts. Thousand Oaks: Sage.

Thurston, Nick (2013). On the Subcontract. York: Information as Material.

Vila-Matas, Enrique (2000). Bartleby y compañía. Barcelona: Anagrama. 